\title{
The current epizootic situation of rabies in Tajikistan
}

\author{
A.A. Muminov ${ }^{1}$, O.D. Nazarova ${ }^{1, *}$, O.G. Petrova ${ }^{2}$, F.B. Kamolzoda ${ }^{1}$, and F.Kh. Pulotov ${ }^{1,3}$ \\ ${ }^{1}$ Tajik Academy of Agricultural Sciences, Institute for Problems Biological Safety and \\ Biotechnology, Dushanbe, Republic of Tajikistan \\ ${ }^{2}$ Ural State Agrarian University, Ekaterinburg, Russia \\ ${ }^{3}$ Tajik National University, Dushanbe, Republic of Tajikistan
}

\begin{abstract}
According to the Terrestrial Animal Health Code and the Veterinary Legislation of the Republic of Tajikistan, veterinary authorities register, give passport and vaccinate dogs and cats, but not to the full extent, which increases the risk of infection and death of people and animals with the rabies virus. This article presents the results of retrospective analysis of the epizootic and epidemiological situation and the role of carnivores and other animals in the circulation of the rabies virus in natural foci in Tajikistan's regions close to big cities and areas under protection. Research and monitoring of the manifestation of rabies among carnivorous mammals in 4 regions of the country were carried out and the role in spreading of rabies infection was studied. As a result of study it was found that the most disadvantaged areas with high levels of rabies infection are Khatlon region and Central Tajikistan, and was explored connection between diseases of dogs and farm animals, especially cattle.
\end{abstract}

\section{Introduction}

The classical form of rabies is common in many countries and is a major cause of disease of animals and humans with rabies. Other lyssaviruses are spread in limited areas and in most cases disseminators are bats $[2-3,10]$. The rabies virus may infect all warmblooded animals [6,9-10].

Given the epidemiological danger of rabies state veterinary services on the fields carry out regular vaccination, registration and certification of dogs and cats, but not to the full extent including in the capital - Dushanbe, which increases the risk of infection and mortality of animals and people from rabies [2,3,5]. In 2015 by the World Health Organization (WHO), the World Organization for Animal Health (OIE), Food and Agriculture Organization (FAO) and the Global Alliance for Rabies Control (GARC) launched "the Global Strategic Plan to prevent deaths from canine-borne rabies by 2030". OIE developed scientific standards on the prevention and control of rabies which were adapted in each country taking into account local conditions. This includes the provisions approved by the OIE official program for the control of dog-borne rabies, control of the

* Corresponding author: orzugul@mail.ru 
population of stray dogs, control of the international movement of dogs and cats, especially in the regions with high levels of rabies infection [4], and introduction of methods of rabies diagnostics and production of veterinary vaccines. In Europe rabies persists in nature in many species of animals from the Canidae family. These are red foxes and jackals in Central and Southern Europe, wolves and raccoon dogs in Northern Europe. Raccoons, coyotes and bats are reservoirs of rabies in the Americas and some Central Asian countries [2,3,6,7,9,10]. In 2021 OIE should approve first national programs to combat rabies, which is transmitted by dogs, for countries that have applied for this procedure. Over the past 10-15 years in Tajikistan the death of people from the bites of stray dogs has been annually recorded. Mostly fatal cases of death of people are registered due to untimely access of citizens to medical aid, as well as the shortage and high cost of the vaccine against rabies. In this regard, the study of the epizootic situation and the development of measures for the prevention of rabies among animals to ensure the prevention of the disease of rabies in the environment and humans remains actual to the present times.

\section{Materials and methods}

For epizootic monitoring and study of epizootic situation were used archival materials and information of veterinary bodies of Food Safety Committee under the Government of the Republic of Tajikistan and the long-term scientific research data of the Institute of Biological Safety and Biotechnology of TAAS. For monitoring and studying the epizootic situation were applied generally accepted methods on epizootic studies $[1,8]$.

\section{Research results}

Rabies is reported annually in many countries including Tajikistan. Studies of the dynamics of manifestations of rabies around the world from 2016-2020 years show that rabies were observed in many countries, including bordering countries with Tajikistan which have close trade and of touristic ties with it, such as China, Afghanistan, Kyrgyzstan, Uzbekistan, Kazakhstan, Russian Federation, Iran and others, which increases risks of bringing the rabies virus into the country.

In spite of the reduction of epizootic process in comparison with the previous years the risk of the inflammation of the disease remains high. In this regard, we analyzed archival and operational data of the veterinary entities of the Food Safety Committee under the Government of the Republic of Tajikistan and the long-term data of scientific researches of the Institute of Biological Safety and Biotechnology of the TAAS for the last 45 years (1976-2020) on incidences of rabies of agricultural and wild animals.

As a result of studies and analysis was found that in Tajikistan over the past 45 years, the entire 3671 (annual average of 81, 62 cases) cases of rabies have been reported, including in Khatlon region -1018, Districts of Republican Subordination (DRS) - 1417, in the Sughd region - 1229 and in the Gorno-Badakhshan Autonomous Region (GBAO) - only 7 cases.

The highest rate of infection of animals of the study falls on a time period of 1976-1985. 758 cases were observed during this period with an average of 63,16 cases per year. In the following decades (1986-1995) the number of rabies infection among animals were much reduced, in all, it was noted 653 cases or 54,4 cases per year. For the period of 1996-2005, were registered 1044 cases of rabies with an average of 87 cases per year. Epizootic situation in the republic over the years have worsened due to animal rabies and only for the period of 1986-1995 years there was a slight improvement in the epizootic situation 
compared to previous years. Over the past 5 years (2016-2020), 329 cases of an outbreak of rabies infection among animals were registered, which is 65,8 cases per year (Fig. 1).

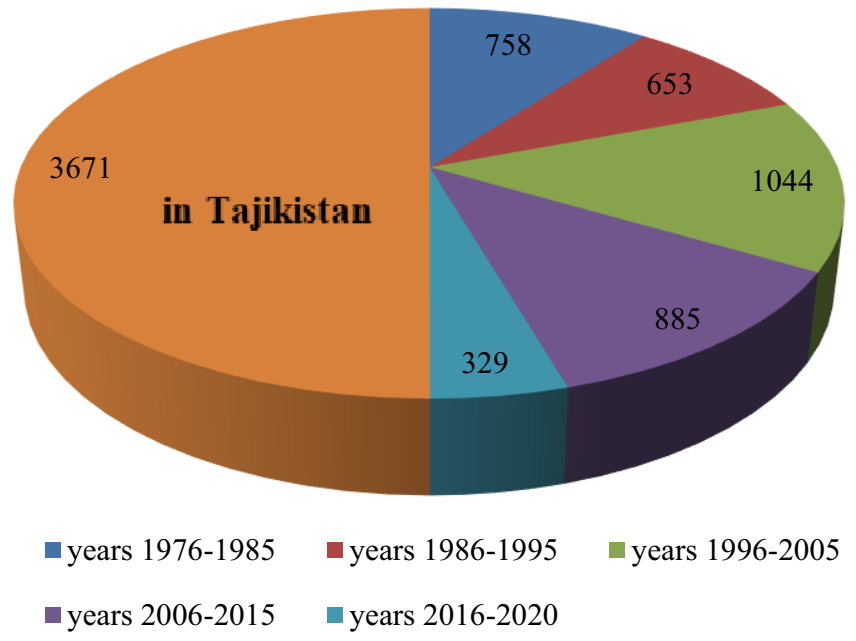

Fig. 1. Dynamics of the inflammation of rabies among animals in Tajikistan for 1976-2020 years.

We also studied and analyzed the incidence of rabies of animals for the period of 19762020 in the regions of Tajikistan with different climatic and geographic conditions. As a result of laboratory analysis and of operational data, it was established that the rabies virus circulates throughout the territory of the republic among animals of various species. Despite of this most disadvantaged areas are Districts of Republican Subordination (DRS). Between 1976 and 2020, 1,417 (annual average 31,49) cases of rabies of animals were reported in the DRS. In Sughd and Khatlon regions were respectively observed 1229 (27,31 cases per year) and 1018 (22,62 cases per year) cases of rabies outbreaks and in GBAO for 45 years, was found only 7 cases of rabies in domestic and in wildlife. 2006-2015 were the most unfavorable for DRS, where 480 cases of infection were noted (48 cases per year), and for Sughd and Khatlon regions, the period from 1996-2005 with respectively 376 (37,6 per year) and 282 (28,2 per year) cases of rabies (Fig. 2, 3 and 4 ).

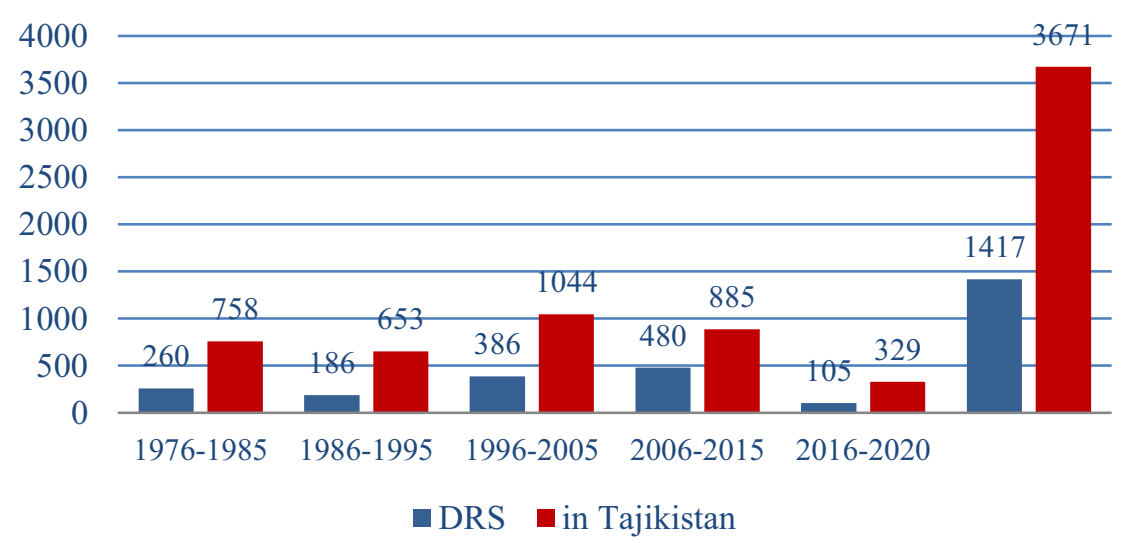

Fig. 2. Dynamics of rabies morbidity in animals in Districts of Republican Subordination 1976-2020 years. 
It should be noted that in recent years' complex epizootic situation of rabies of animals were established on the territory of Khatlon region, where there are 6 natural areas under protection with a large number of wild carnivores. Analysis of the data shows that the registration of rabies cases among animals has been constantly increasing in recent years. The most unfavorable situation of animal rabies is observed in the districts of Kushoniyon, Vakhsh, Balkh, Khuroson, Bokhtar and Temurmalik, as well as the cities of Levakand, Bokhtar and Nurek. The highest number of rubies among animals noted in the regions of republican subordination Rudaki, Vakhdat, Fayzobod, Rasht, Sharinav and the cities of Dushanbe, Vakhdat and Gissar. The territories of abovementioned districts and cities are densely populated with the highest number of farm animals in the households.

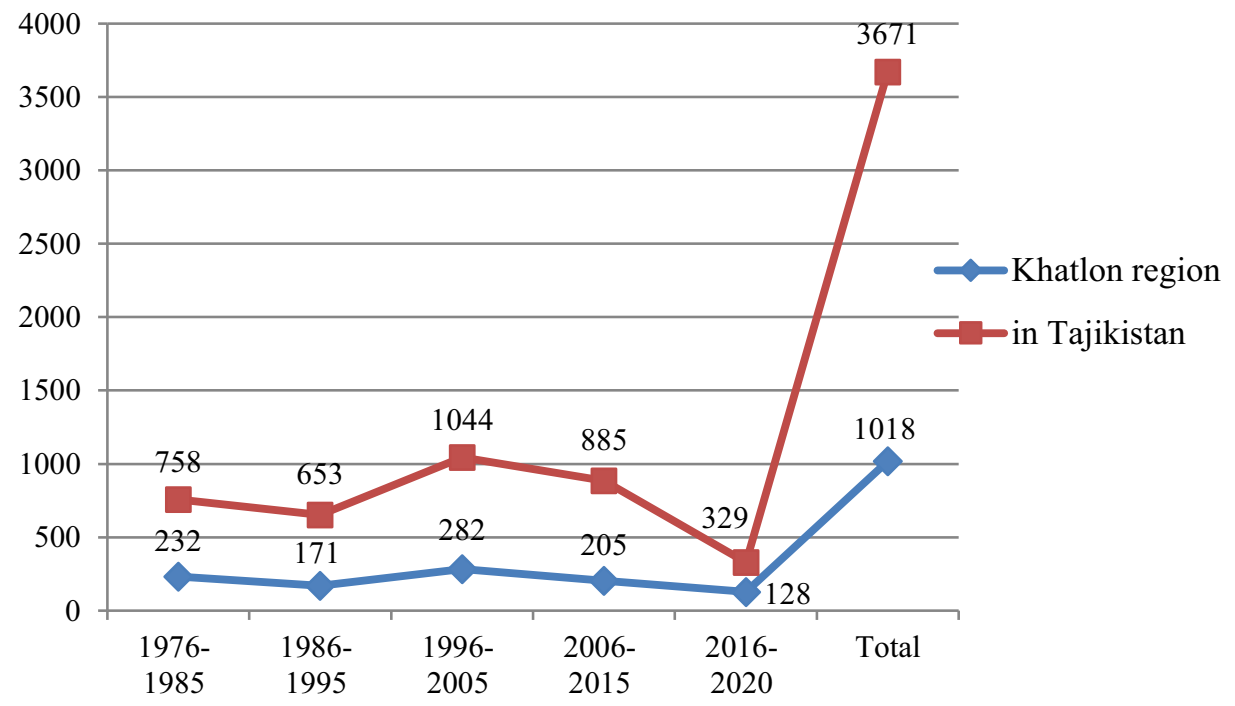

Fig. 3. Dynamics of the incidence of rabies in animals in the Khatlon region for 1976-2020 years.

As it was already noted the highest rate of rabies among animals have been registered in the densely populated region Sughd, North of Tajikistan. For the period of 2016-2020, 93 $(18,6$ cases per year) cases of rabies among animals were noted (Fig. 3). It should be noted that in addition to wild and domestic carnivores, farm animals were also affected by the epizootic process of rabies. So if in 2020, 18 cases of rabies among animals were noted in the region, 4 of them are farm animals. The prevalence of morbidity among animals is noted in the districts of B.Gafurov, Kanibadam, Zafarabad and the cities of Guliston and Khujand. 


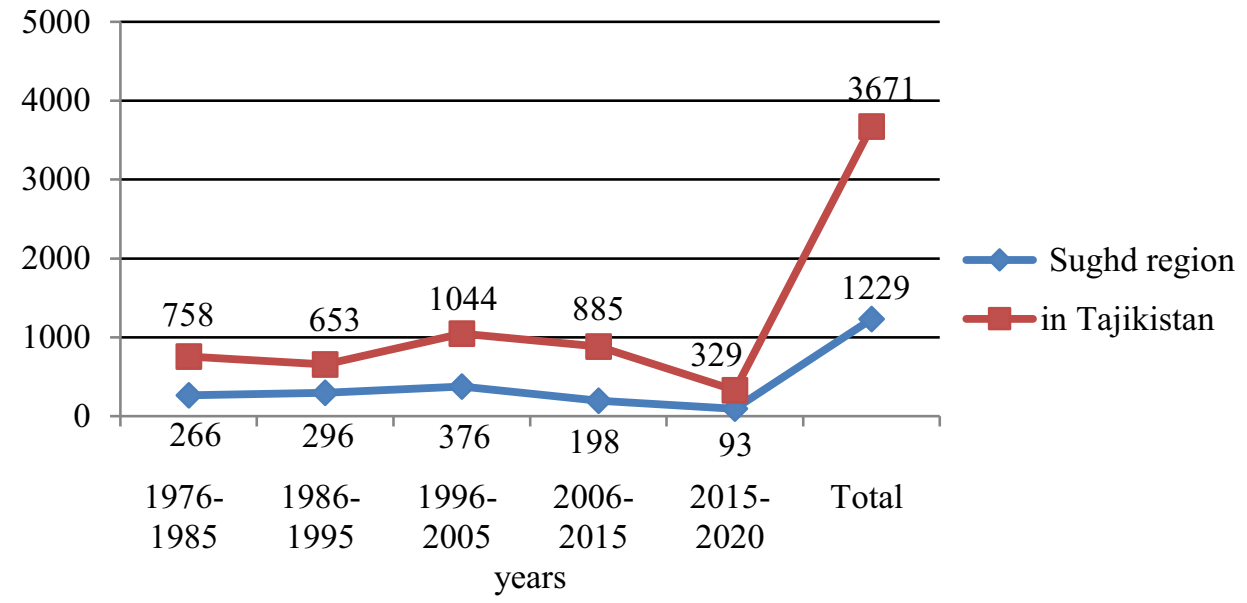

Fig. 4. Dynamics of animal morbidity with rabies in Sughd region for 1976-2020 years.

We have also studied the involvement of various animal species with rabies in the epizootic process over the last 5 years (2016-2020). Analysis of the data shows that over the past 5 years, rabies has been predominantly observed among meat-eating animals, that is, dogs. Among all infected animals the total number of sick animals, 69,39\% are dogs. In terms of the number of infected, cattle rank second $-21,81 \%$. The incidence among other types of domestic and wild animals such as horses, donkeys, yaks, cats, wolves, foxes, rats and others is $8,78 \%$. It should be noted that the incidence of sickness in animals in the republic in 2019 compared to 2016 decreased by $54,16 \%$. animals in disadvantaged regions and border areas of Tajikistan. So if in 201678351 (120\%) animals were vaccinated of which $68481(87,40 \%)$ were dogs, then in 2019 the total number of vaccinated cattle increased up to $157312(150 \%)$, but the number of vaccinated dogs decreased to 76672 $(49,37 \%)$. It should be noted that despite the high coverage of dogs with vaccination, out of 96 cases of disease, $64(66,66 \%)$ were observed among dogs and $26(27,08 \%)$ among steep cattle. Whereas in 2019 , only 53 cases of rabies were registered, of which $41(77,35 \%)$ were among dogs and $4(7,54 \%)$ were among steep cattle. In this connection, to find out the reasons for the spread of rabies among animals in the republic, additional research will be required (Fig.5, Table 1).

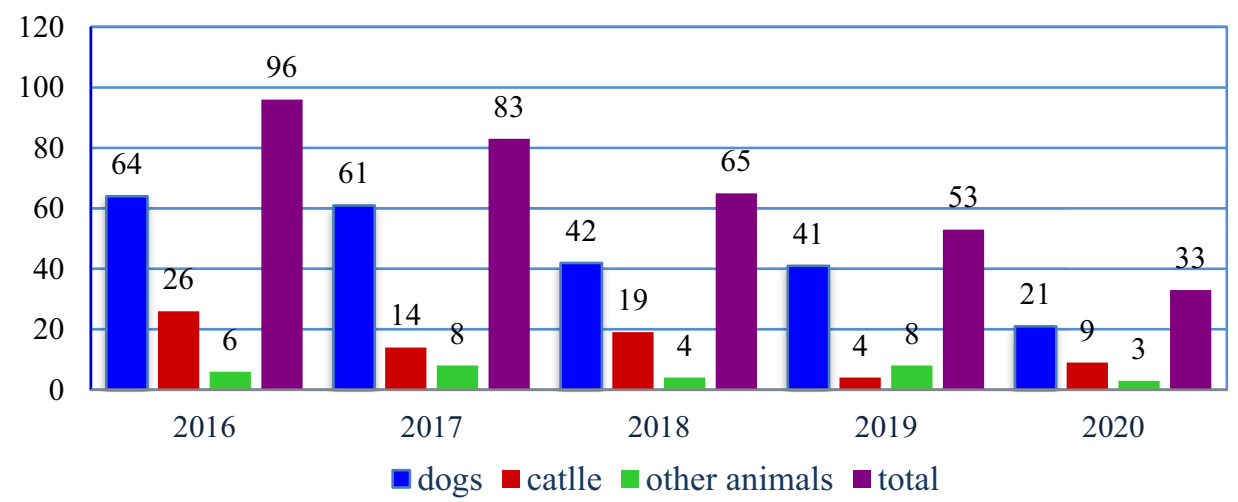

Fig. 5. The incidence of rabies in animals in Tajikistan for 2016-2020 years. 
Table 1. Vaccination of animals against rabies and the incidents of rabies and different in and rows of animals over the past and is, 5 years (2016-2020).

\begin{tabular}{|c|c|c|c|c|c|c|c|}
\hline Years & \multirow{2}{*}{$\begin{array}{c}\text { Total } \\
\text { vaccinated } \\
\text { (head \%) }\end{array}$} & \multicolumn{2}{|c|}{ Of them } & \multicolumn{3}{|c|}{ Cases of rabies animal protection } \\
\cline { 3 - 9 } & $\begin{array}{c}\text { Dogs } \\
\text { (head\%) }\end{array}$ & $\begin{array}{c}\text { Cats } \\
\text { head \%) }\end{array}$ & $\begin{array}{c}\text { Dogs } \\
\text { (head \%) }\end{array}$ & $\begin{array}{l}\text { Cattle } \\
\text { head \%) }\end{array}$ & $\begin{array}{l}\text { Others } \\
(\text { head \%) }\end{array}$ & Total \\
\hline 2016 & $78351(120)$ & $68481(87,40)$ & 3355 & 64 & 26 & 6 & 96 \\
\hline 2017 & $120262(115)$ & $59457(49,43)$ & 2385 & 61 & 14 & 8 & 83 \\
\hline 2018 & $86979(130)$ & $44399(51,04)$ & 1811 & 42 & 19 & 4 & 65 \\
\hline 2019 & $157312(150)$ & $76672(49,37)$ & 1237 & 41 & 4 & 8 & 53 \\
\hline 2020 & $73581(100)$ & $36630(49,78)$ & 5469 & 21 & 9 & 3 & 33 \\
\hline Total & $516485(115)$ & $285639(55,30)$ & $14257(2,8)$ & $229(69,39)$ & $72(21,81)$ & $29(8,78)$ & 330 \\
\hline
\end{tabular}

\section{Epidemiological situation on rabies in Tajikistan}

One of the criteria for the country's epizootic well-being is the country's epidemiological state of zoonotic infections, one of which is rabies. In this regard, we studied the number of bites and the incidents of rabies of people. Analysis show that annually medical organizations in Tajikistan register from 7 to 14 thousand bites among the population. As can be seen from the data in the figure, the incidents among people decreases from year to year, if in 200123 people fell ill, then in 2009 - 7 people, and in 2020 their number decreased to 4 people. Despite this, veterinary and medical authorities must not lose sight on prevention of this terrible and incurable disease (Fig. 6).

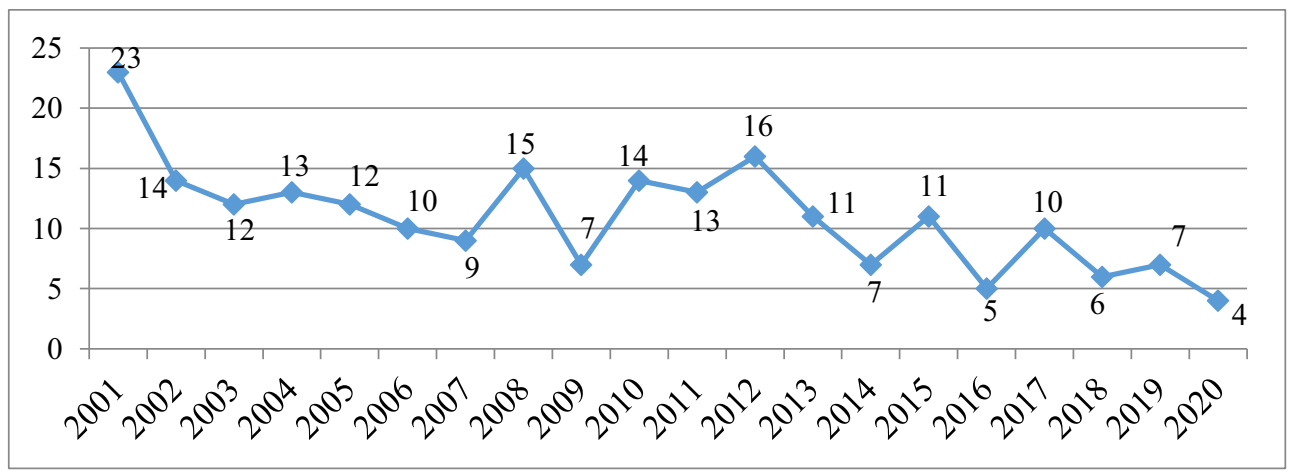

Fig. 6. Human morbidity with rabies in Tajikistan for 2001-2020 years.

\section{Discussion}

Thus, as a result of studies of the dynamics of the manifestation of rabies, it was established that although the epizootic process of the disease on the territory of the republic has improved significantly compared to 2014, the situation remains difficult. As, according to some researches result epizootic infections with rabies except domestic and wild animal bats are also involved in the process [2,3].

It also raises concerns that, for the period of 1976-2020, 3671 cases of rabies among animals of various species were registered in the republic, which is an average of 81,62 cases annually. Among animals, rabies are noted at all seasons, but the situation is mostly aggravated in autumn - winter and winter - spring periods of the year, which is associated with the period of biological reproduction of wild and domestic meat-eating animals [5].

The processing and analysis of statistical data and the results of our research for the period of 1976-2020 shows that rabies is mainly registered in the southern part of the country and accounts for $66,32 \%$ of the total number of animal diseases, of which $38,59 \%$ in DRS, $27,73 \%$ in Khatlon region, and in the northern part of the country accounts for 
$33,47 \%$ of the total number of cases and $0,21 \%$ in GBAO. At the same time, it should be noted that cases of rabies among animals were noted both in the territories of previously unfavorable, and in the territories of regions previously free from this disease. This indicates the emergence of new unsuccessful rabies cases in the southern part of the country, with many of them bordering on rabies-unsuccessful regions of neighboring countries, in particular Afghanistan.

\section{Conclusions}

It was established that on the territory of Tajikistan for the last 5 years (2016-2020) more than $69,39 \%$ of the cases of rabies occurred among dogs $21,81 \%$ among cattle and only $8,78 \%$ of cases among other species of animals. It was revealed new dysfunctional points of rabies on territories formerly of prosperous regions.

The peak of rabies incidence in the regions of Tajikistan falls on different decades, which indicates the influence of local natural and socioeconomic conditions on the epizootic process of animal rabies.

In the conditions of Tajikistan, a direct relationship has been revealed between the incidence of diseases in dogs and cattle, as well as between animals and humans.

It was found that in the country the incidence of rabies among people decreases from year to year, but the risk of the virus being brought in from outside and morbidity of human beings still remain.

\section{References}

1. P.G. Gorbenko, A.D. Alekseev, O.G. Petrova, MEDICUS International medical scientific journal, 3(21), 10-16 (2018)

2. L.G. Gulamadshoeva, A.N. Mamadshoev, K.Kh. Khamroev, T. Tilloev, Veterinary Medicine, Animal Science and Biotechnology, 8, 578-582 (2016)

3. L.G. Gulamadshoeva, T.V. Grebennikova, M.M. Anoyatbekov, A.N. Mamadshoev, A.N.Shabeikin et eth, Veterinary and feeding, 6, 24-34 (2016)

4. Terrestrial animal health code, Paris, France 8.13, 2, (2019)

5. G.N. Mamadatohonova, Epizootological aspects of rabies in Tajikistan, Extended, 22 (Abstract of Diss. Can. Sci. Vet. Krasnodar, 2019)

6. G.G.Onishchenko, A.Yu. Popova, E.B. Ezhlova, Yu.V. Demina, N.D. Pakskina, M.N. Pistsov, V.V. Rubtsov, A.V. Surovyatkin, A.A. Petrov, A.V. Kazantsev, A.M. Berezhnoy, A.Yu. Zverev, A.V. Manoshkin, V.T. Krotkov, D.A. Kutaev, V. A. Maksimov, S.L. Kuznetsov, E.Yu. Vakhnov, M.A. Timofeev, A.A. Movsesyants, S.V. Borisevich, Problems of especially dangerous infections, 3, 27-32 (2017)

7. E.G. Simonova, Epidemiology and vaccine prevention, 17(5), 31-37 (2018)

8. E.G. Simonova, S.R. Raichich, S.A. Kartavaya, N.N. Filatov, Journal of Microbiology, Epidemiology and Immunobiology, 3, 77-83 (2017)

9. L.K. Saryglar, Animal rabies spresding in the republic of Tyva, Bulletin KrasGAU, 2, 93-97 (2020) DOI: 10.36718 / 1819-4036-2020-2-93-97

10. V.V. Nikiforov, M.G. Avdeeva, ACTUAL ISSUES, Epidemiology and Infectious Diseases (Russian Journal), 22 (6), 295-305 (2017) DOI: 10.18821 / 1560-9529-201722-6-295-305 